\title{
Size-dependent colouration in larvae of Orgyia antiqua (Lepidoptera: Lymantriidae): A trade-off between warning effect and detectability?
}

\author{
SIIRI-LiI SANDRE, TOOMAS TAMMARU and TRIINU MÄND
}

\begin{abstract}
University of Tartu, Institute of Zoology and Hydrobiology, Vanemuise 46, 51014 Tartu, Estonia, e-mails: siiri-ly@ut.ee;
\end{abstract} tammarut@ut.ee; triinum@ut.ee

Key words. Aposematism, predator-prey interaction, colouration, body size, Lymantriidae, detectability

\begin{abstract}
While the study of colour patterns is a traditional subject of evolutionary ecology, there are various hypotheses which suffer from a lack of experimental evidence. One intriguing possibility is a trade-off between warning efficiency and detectability. After a certain size threshold, the detrimental effect of increased detectability can outweigh the benefits of warning colouration. One may thus expect corresponding patterns at the level of ontogenetic development: as juveniles grow, they should first acquire warning colouration, and then lose it again. We analysed this possibility in Orgyia antiqua, a moth species with hairy larvae which are polyphenic with respect to the intensity of warning colouration. We detected a regular change in colour patterns through larval life. Indeed, the larvae tend to display warning colouration at intermediate sizes while dull colours dominate in fully grown larvae. In aviary experiments, we confirmed that the colourful phenotype is the one that causes the strongest aversion in birds. Nevertheless, the effect was rather weak and most of the larvae were still eventually consumed when found. Unexpectedly, for human subjects, the warningly coloured larvae were harder, and not easier to find among natural vegetation, most likely due to the disruptive effect of the aposematic colour pattern. Importantly, the trend was reversed in the largest size class, suggesting that the disruptive colouration loses its advantage as the larva grows. This is consistent with the actual patterns of size-dependence of colouration. We present evidence against an alternative explanation which relates size-related change in colouration to behavioural changes prior to pupation. We conclude that even if the efficiency of the warning effect plays a role in determining the size-dependence of colouration, the pattern may be largely explained by the effects of size-dependent detectability alone.
\end{abstract}

\section{INTRODUCTION}

Colouration is one of the most apparent traits of every organism. Different colour patterns serve functions that range from camouflage to signalling about the status of an individual in advanced social systems. Adaptationist explanations of different colour patterns represent the classic subjects of evolutionary ecology (e.g. hoverflies as batesian mimics of wasps, Mostler, 1935; eyespots on butterfly wings, Blest, 1957). Nevertheless, quite paradoxically, many such textbook examples appear to lack satisfactory experimental proofs (Ruxton et al., 2004), quite likely because they became classics before contemporary experimental protocols were established in evolutionary ecology (e.g. industrial melanism: Tutt, 1896, but see Sargent et al., 1998; countershading: Poulton, 1888, but see Kiltie, 1988).

In particular, some of the under-explored questions are related to the cases in which a trade-off between different functions of a colour pattern is expected. As an example, warning function is likely to be traded for higher apparency to natural enemies (the trade-off hypothesis, hereafter). On the one hand, any visual warning signal is the more efficient the larger it is (Gamberale \& Tullberg, 1996, 1998; Lindström et al., 1999b), and large warning signals can only be displayed on large bodies (Forsman \& Merilaita, 1999). This inherent size-dependence of warning efficiency leads one to expect aposematic colouration more frequently among large animals, rather than in small ones (Forsman \& Merilaita, 1999, Hagman \&
Forsman, 2003; Nilsson \& Forsman, 2003). In turn, conspicuous colouration also increases prey detectability by any visually searching predator. Quite obviously, detectability is higher if the body is larger, and, somewhat less obviously, there is some evidence that aposematic prey has a steeper size dependent detectability function, as compared to cryptic objects (Mänd et al., 2007; this study). This is biologically relevant because warning colouration rarely offers complete protection to the aposematic prey (Stimson \& Berman, 1990; Geffeney et al., 2002; this study), and high detectability may thus be highly detrimental (Exnerová et al., 2003, 2006; Endler \& Mappes, 2004). Such a trade-off situation may imply that warning colouration is the optimal solution for some intermediate body sizes, while most animals smaller and larger than that are selected to be cryptic, i.e. after certain size thresholds, the cost of being detected is not outweighed by the benefits of the warning signal.

A pattern consistent with this hypothesis can be seen at the level of interspecific comparisons. In particular, while it is well appreciated that the smallest insects are usually inconspicuous, it is noteworthy that, in temperate areas at least, the largest ones are also only rarely warningly coloured, and cryptic colouration tends to prevail. For example, among the European macrolepidopteran larvae, a definite warning colouration occurs most often among species of intermediate body sizes (about 200-500 mg of pupal weight; Porter, 1997). In contrast, the largest lepidopterans, e.g. most sphingids, saturnids and lasio- 
campids are typically characterised by cryptically coloured larvae. Consistent with this trade-off hypothesis, is the observation that in some snakes both warning colouration (Madsen, 1987) and locomotive warning displays (Bonnet et al., 2005) are reduced as the individuals grow larger. However, in the case of prey species that are relatively large in comparison to their predators, an alternative explanation for this phenomenon could be individuals reaching a "size refugium" (Paine, 1976; Holopainen et al., 1997; Chase, 1999), i.e. the largest individuals cease to be vulnerable to predators, which renders warning displays unnecessary.

In holometabolous insects at least, it is common that younger, smaller-bodied developmental stages are cryptic, and the aposematic species acquire their typical warning colouration in their later larval instars, or in the adult stage (Bernays \& Montllor, 1989; Ulmer et al., 2003; Sandre et al., 2007). However, following the rationale of the trade-off hypothesis, one should expect also an ontogenetic change in the opposite direction, i.e. in large insects, warning colouration displayed at the intermediate stages should be replaced by a cryptic one as the body grows. Although the pupae of insect species with conspicuous larvae are known to be typically cryptic (Wiklund \& Sillen-Tullberg, 1985), such a change during the larval stage has not, to our knowledge, been frequently documented (the few positive examples seem to be causally related to switching from aggregated to solitary lifestyle: Cornell et al., 1987; Costa et al., 2003). Nevertheless, each such attested case could provide an important piece of evidence in favour of the trade-off hypothesis, or its possible alternatives, and would contribute to our understanding of the evolution of colour patterns in general.

In the present study, we evaluate the possibility that a trade-off between warning efficiency and camouflage forms an ultimate explanation for the dependence of colour pattern on the developmental stage in the larvae of a moth species. We first analysed the dependence of colour pattern on body size, with an emphasis on distinguishing between the intercorrelated effects of size, instar number, and sex. Further, we studied the responses of bird predators to differently coloured larvae to test for differences in the warning efficiency of these colour patterns. Finally, we evaluated the detectability of differently coloured and sized larvae in experiments with human subjects. We interpret our results as supporting the trade-off hypothesis only partly; this is because the patterns of dependence of detectability on size may alone be sufficient to provide an explanation.

\section{MATERIAL AND METHODS}

\section{Study species}

Orgyia antiqua (Linnaeus, 1758) (Lepidoptera: Lymantriidae) is a diurnally active moth species with a broad holarctic distribution. The solitary polyphagous larvae typically pass through 4 to 5 (males) or 5 to 6 (females) instars. By having on average one extra larval instar than males, the females attain three to four times higher pupal weights than do the males (Esperk \& Tammaru, 2006). The ultimate reason for such a high level of sexual size dimorphism lies, most likely, in the strong correlation between female body weight and fecundity (Tammaru et al., 2002). The pupal weights vary usually from 80 to $500 \mathrm{mg}$ but a few individuals as large as $650 \mathrm{mg}$ have been recorded in our rearings. The egg is the overwintering stage; the adults fly in August and September, and the larvae thus develop in midsummer.

The larvae of $O$. antiqua are hairy with blackish background colour. In the first three instars - most likely mimicking bird droppings - the larvae lack any conspicuous colour pattern, as well as long hair. From the 4th larval instar onwards, however, they have four conspicuous dorsal hair tufts on their 4 th to 7 th body segments. The colour patterns of the hair tufts classify into one of three distinct classes: (1) two black anteriorly and two yellow posteriorly, (2) all four bright yellow, or (3) all four brown. Henceforth, these morphs will be labelled as pied, bright and $d u l l$, respectively. The first two phenotypes are nearly monomorphic but within the dull class, there is a continuous variation from dark yellow to dark brown. This conspicuous polyphenism affects only the large dorsal tufts. There are no obvious differences in the colouration of other body parts: the dark gray hairless cuticula, tiny red spots laterally on each segment, and two tiny red glands dorsally on the 6 th and 7 th abdominal segment (Deml \& Dettner, 2001), blackish tufts just behind the head, laterally, and at the posterior tip of the body.

In a previous study (Sandre et al., 2007), we showed that the colour polyphenism in $O$. antiqua is proximately based on individually variable concentrations of a carotenoid pigment (lutein). The variation in the colouration has both a genetic and an environmental component. However, we were unable to demonstrate an effect of host plant on larval colour pattern (Sandre et al., 2007), nor was the colour pattern dependent on rearing temperature (Sandre et al., in press). Notably, however, the frequency of colour morphs was found to differ between larval instars: most typically (but not invariably) a larva is pied in its 4th instar, bright in the 5th, and dull in the 6th instar (Sandre et al., 2007) with the larvae switching from one morph to another in connection to moulting. From the data analysed at the level of particular instars, it remained unclear if such a pattern is primarily attributable to larval instar, body size, or sex. Our experience indicates that these variables are intercorrelated.

\section{Rearing experiments}

Data used for the analysis of the associations between colour morph and body size, sex and instar, were obtained from four laboratory rearing experiments. These were carried out in summers of 2002 and 2003, in Tartu, Estonia. The larvae of $O$. antiqua of Estonian and Finnish origin (599 in total, offspring of 20 females) were reared singly in $50 \mathrm{ml}$ plastic vials, they were fed ad libitum with the leaves of their host plants (most on Betula pendula, others on Salix caprea, S. myrsinifolia, S. viminalis, Quercus robur, Cotoneaster lucidus) which were renewed regularly (see Sandre et al., 2007, for further technical details). The insects were monitored throughout their larval lives, and weighed during the inactivity periods preceding each larval moult, to obtain individual-specific initial weights of each instar. Colour morphs were determined by visual inspection on 2 nd day after moulting into each successive instar. The insects were sexed as pupae.

The dependence of colour morph (as a binary response variable) on body size was analysed by logistic regressions on a data set consisting of relevant data for each instar (starting from the 4th) of each individual larva. In the first analysis, the ontogenetic switch from the pied morph to the unicolored phenotype (bright and dull pooled) was considered. In the second analysis, the switch from bright to dull morph was examined. Both cases 
were analysed in two different ways: first, the net effects of weight at moulting, sex, and instar were evaluated in respective one-way logistic regressions; second, a conservative estimate of each of these effects was obtained from a three-way analysis with all these arguments included simultaneously (Table 1). In the second analysis (i.e. bright vs dull), the effect of sex could only be tested in the 5th instar larvae because all 6th instar larvae were females.

\section{Acceptability tests}

Experiments with captive birds (great tits, Parus major) were performed to compare the warning efficiency of different larval colour morphs of $O$. antiqua. The trials were carried out, with appropriate permission from the Estonian Ministry of Environment, at Kabli Bird Station in Estonia. The great tits had been trapped on passage during autumn migration in October 2005 . The birds were left to settle in individual cages $(80 \times 80 \times 80$ $\mathrm{cm})$ for $2 \mathrm{~h}$, and were released immediately after the experiment. Only the birds which started to eat sunflower seeds within this period were used for the experiments. Two birds showing no motivation to feed were released.

Attack delay (= attack latency, or hesitation time), i.e. the time interval from noticing to touching the prey by the bird was used as the inverse measure of acceptability of the larva (e.g. Hagen et al., 2003). This variable was measured for each prey item presented. If the bird did not touch the larva within 10 minutes, the particular trial was terminated. In total, there were 13 such tests with pied, 15 with bright and, 16 with dull larvae. To avoid pseudoreplication, each individual bird, as well as each larva, was used only once. As natural variation in the hunger level of an individual was previously shown to influence attack delay, this parameter was also measured by recording the number of blowfly pupae consumed after the trial (Sandre \& Mappes, in prep.). The Orgyia larvae presented had been frozen alive, and live weight before freezing was thus the measure of body size used in the analyses. Using dead larvae in a predation experiment is not expected to lead to a substantial bias. This is because Orgyia larvae are relatively immobile and typically found exposed on plant leaves; neither do they appear to display any warning behaviour. The dependence of attack delay (logarithmically transformed to normalize distributions) on colour morph, larval weight, and hunger level was analysed by ANCOVA.

\section{Detectability trials}

Experiments to evaluate the detectability of $O$. antiqua larvae, as dependent on colour morph and body size were performed with human subjects. Humans were used in this experiment because measuring the detectability of aposematic prey to its natural predators is problematic: the predators might avoid the prey, and this would flaw the results. For the experiments, we chose 9 pairs of similarly sized larvae that represented different colour morphs: one larva within each pair was bright whereas the other larva was dull. The average live weights of the larvae in the pairs covered the range of sizes from 64 to $271 \mathrm{mg}$. The larvae were killed by freezing, and then glued to leaves of blueberry (Vaccinium myrtillus). The so prepared pairs of larvae were placed, one at a time, in a square of $1 \times 1 \mathrm{~m}$. The square was divided into 100 equal-sized subsquares which were numbered, and the exact position (i.e. the number of the subsquare) of each of the larvae within a pair was decided by using a randomisation procedure (http://www.randomnumbers.info/) for numbers from 1 to 100 . The experiment was replicated on two different substrates: a freshly mown $(5 \mathrm{~cm}$ high) semi-natural lawn, and, alternatively, fresh shrubs of blueberry (a frequently used host of $O$. antiqua), cut from a natural habitat.
TABLE 1. $\chi^{2}$ statistics $(\mathrm{df}=1)$ for factors explaining the variation in larval colouration (as a binary variable) in one-way logistic regression models (total), and in alternative multi-way models (conservative) with all the explanatory variables listed in the table, as well as brood and experiment identity simultaneously included.

\begin{tabular}{lrc}
\hline Effect & Total & Conservative \\
\hline Pied vs. bright & & \\
$\quad$ Weight & $156.0^{*}$ & $47.8^{*}$ \\
Sex & $63.0^{*}$ & $69.2^{*}$ \\
Instar & $82.3^{*}$ & 0.4 \\
Bright vs. dull & & \\
Weight & $118.0^{*}$ & $97.9^{*}$ \\
Sex (only 5th instar) & $112.0^{*}$ & $35.7^{*}$ \\
Instar & $31.2^{*}$ & 0.06 \\
\hline$* \mathrm{p}<0.0001$ & &
\end{tabular}

Human subjects (10, in total) were instructed to search for the larvae in the setting described above. Time to finding each of the larvae (the bright and the dull one) was recorded. The differently sized pairs were presented to each subject in a random order. Additionally, artificial larvae of similar appearance (dark grey plasticine with four yellow or brown painted dots) were used to estimate the detectability of sizes larger (length $4 \mathrm{~cm}$, corresponding to a $600 \mathrm{mg}$ Orgyia larva) than were found in our rearing, and a small one to provide a reference point $(1.2 \mathrm{~cm}$, of the size of an average 3rd instar larva, with approxinate weight of $36 \mathrm{mg}$ ). As a result, each subject was involved in 22 such trials ( 11 pairs of larvae $\times 2$ substrates).

The data were analysed in two different ways. First, time to detection (logarithmically transformed, to normalize the distribution) of each particular larva was used as the dependent variable in a general linear model with random effects (SAS PROC MIXED, Littell et al., 2002). Larval size (continuous), larval colour (bright vs dull), presentation order (to each subject, continuous), substrate, weather (sunny or cloudy) and position (distance from the centre of the square) were used as fixed independent variables, the identity of the pair of the larvae, and human subject as random effects. The Kenward-Roger method was applied to adjust the number of degrees of freedom to account for repeated measurements on different subjects, and pairs of larvae. Alternatively, just the order of detection (first or second, within a pair) was used as a binary response variable, and studied as dependent on the colour and size of the larvae.

\section{RESULTS}

Correlative analyses clearly showed that body mass at moulting into an instar was the primary determinant of the colour pattern to be displayed in the particular instar. Roughly, at weights below $80 \mathrm{mg}$, half of the larvae were pied, and half were of uniform colouration (bright, and only rarely $d u l l)$. There was a significant difference between the sexes (Table 1: at any given size, males were less likely pied than the females) though the qualitative patterns were not sexually dimorphic. At weights over $100 \mathrm{mg}$, the unicolored females tended to be dull rather than bright (Fig. 1b). Here the pattern differed considerably between the sexes: the relatively few males that moulted in their final instar at weights over $100 \mathrm{mg}$, tended to be bright rather than dull. As a consequence, most males pupated in the bright morph while most 

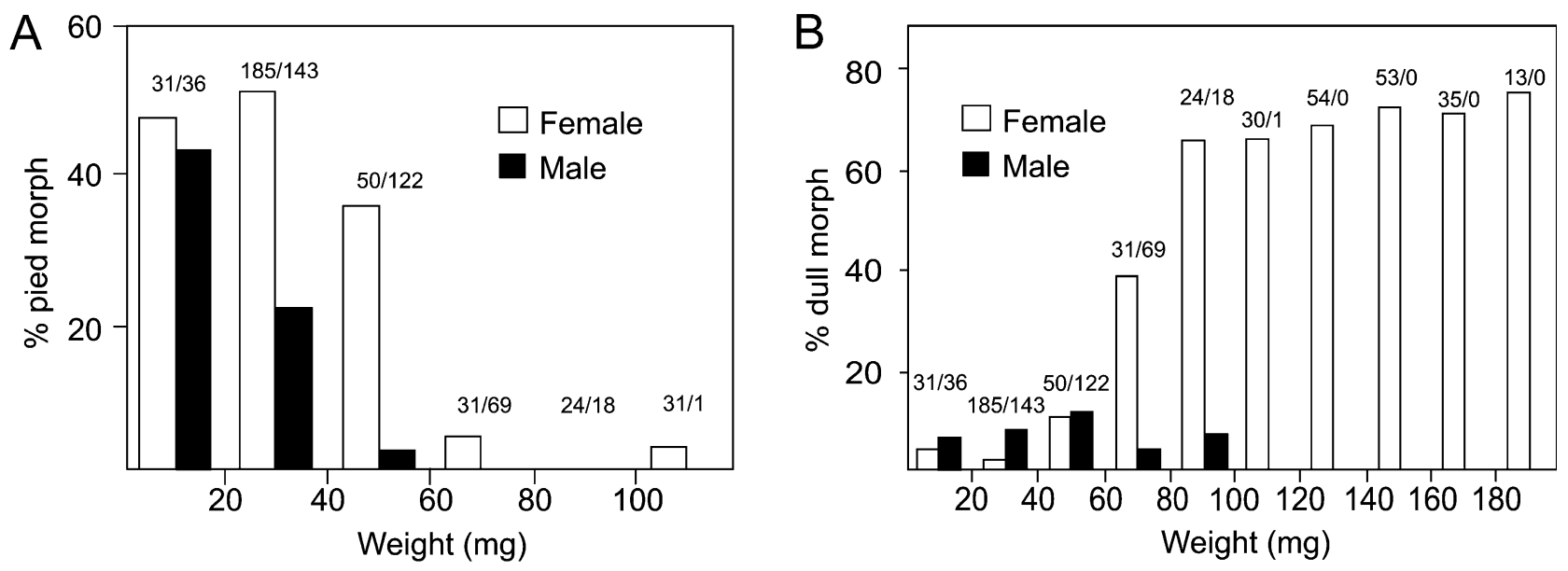

Fig. 1. The percentages of colour morphs in different size classes (according to weight at the beginning of instar) of male and female Orgyia larvae. Panel A describes the switch from pied to the unicoloured (bright and dull pooled) phenotype, panel B the switch from warning (pied and bright pooled) to the dull phenotype. Sample sizes are marked as fractions where the numerator is the number of females and the denominator is the number of males in respective size classes.

females did so in the dull morph. At both switches, instar number had no influence after the effects of size and sex had been accounted for. Moreover, instar number had no effect also when the number of instars was alternatively counted backwards, i.e. starting from the last one.

In the far majority of cases (41 of 44), the birds attacked the $O$. antiqua larva presented, and in most cases (73\%) the larva was also consumed; however, the probability of getting eaten did not depend on the colour morph (exactly 4 larvae of each morph were not eaten). The attack delay was different for the colour morphs (Table 2): the bright morph was treated with more caution than the other two. Body mass of the larvae had no effect on attack delay but the impact of hunger was highly significant (Table 2). None of the interactions between the explanatory variables attained statistical significance.

In the detectability experiments, as the overall effect, the dull larvae were found faster than the equally sized bright ones (Table 3; 25 and $43 \mathrm{~s}$ on average, respectively). No effect of size, background and sunshine was detected, neither was the interaction between size and colouration significant. The effect of size was notably weak when the analysis was limited to real (as opposed to artificial) larvae (Table 3). However, when the detection order was expressed as a rank, we found an evidence of an interaction between size and colour: the largest bright larvae had a disadvantage over dull ones, and were more likely to be detected first, as compared to smaller ones (Fig. 2). When the two artificial larvae were included, the pattern was even more clear (Fig. 2). The qualitative dif-

TABLE 2. Effects of colour morph and weight of the larva on the attack delay of birds. The median values of hesitation were $112 \mathrm{~s}$ for bright, $21 \mathrm{~s}$ for pied and $30 \mathrm{~s}$ for dull larvae.

\begin{tabular}{lccc}
\hline Effect & df & F & $\mathrm{p}$ \\
\hline Colour morph & 2 & 3.10 & 0.050 \\
Weight & 1 & 1.03 & 0.340 \\
Hunger & 1 & 8.14 & 0.007 \\
Error & 44 & & \\
\hline
\end{tabular}

ference between the results with real times, as compared to the ranks, is likely to be explained by the high variation in the absolute times that decreased the power of the analyses, and obscured the patterns.

\section{DISCUSSION}

The colour pattern of $O$. antiqua larvae displayed clear trends, increasing with the age and size of the larvae.

Table 3. The effect of various factors on time to finding bright and dull Orgyia larvae of various sizes (and two pairs of artificial larvae). Human subjects searched for simultaneously presented similarly sized larvae of different morphs from $1 \times 1$ $\mathrm{m}$ squares with different backgrounds. Excluding the nonsignificant effects from the model did not have a qualitative influence on the results of primary importance in present context.

\begin{tabular}{lcccl}
\hline Effect & ndf & ddf & $\mathrm{F}$ & $\mathrm{p}$ \\
\hline Artificial larvae included & & & & \\
$\quad$ colour morph & 1 & 380 & 7.15 & 0.008 \\
weight & 1 & 10.7 & 30.80 & 0.0002 \\
*weather & 1 & 22.3 & 1.15 & 0.29 \\
**background & 1 & 386 & 0.54 & 0.46 \\
***presentation order & 1 & 388 & 3.79 & 0.05 \\
****position & 1 & 391 & 0.21 & 0.60 \\
weight*colour & 1 & 384 & 3.26 & 0.07 \\
Real larvae only & & & & \\
colour morph & 1 & 322 & 4.68 & 0.03 \\
weight & 1 & 9.5 & 2.00 & 0.19 \\
$*$ weather & 1 & 16.7 & 1.29 & 0.27 \\
$* *$ background & 1 & 324 & 0.76 & 0.38 \\
$* * *$ presentation order & 1 & 326 & 2.14 & 0.14 \\
$* * * *$ position & 1 & 326 & 0.01 & 0.91 \\
weight $\times$ colour & 1 & 323 & 1.44 & 0.23 \\
\hline
\end{tabular}

* cloudy or sunny; $* *$ mowed lawn or blueberry; $* * *$ presentation order of pairs of larvae to each subject; **** distance of the larvae from the centre of the square. 


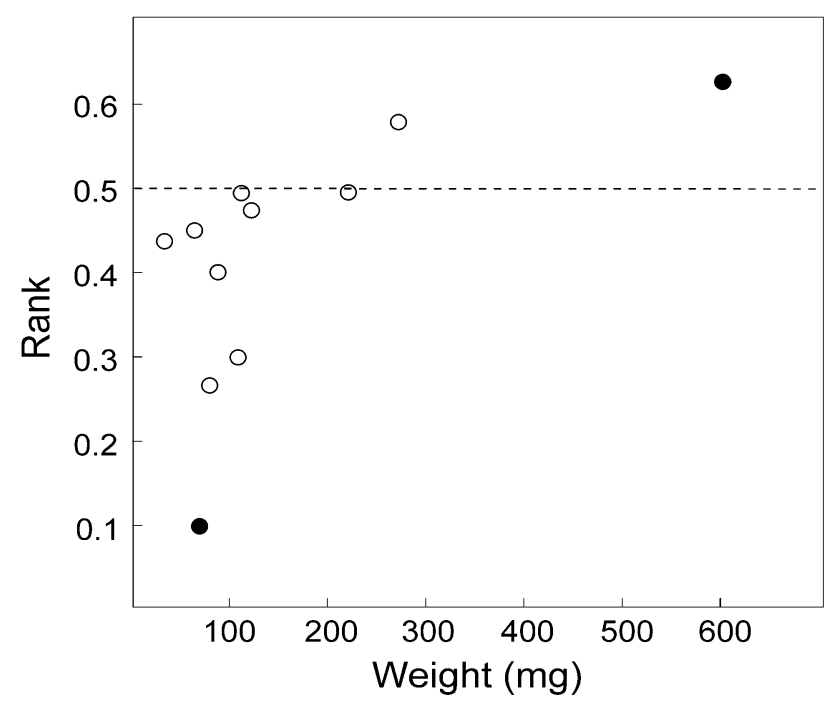

Fig. 2. The probability of the bright larva being detected first by a human subject looking for a bright and a dull larva (a pair) in an experimental arena. The average weight of the larvae within a pair is the independent variable, the dependent variable is the rank ( 1 for being detected first, 0 for being detected second) averaged over the 10 subjects. The two artificial larvae are indicated as black dots. Spearman correlation: $r=0.72, p=0.02$ for natural larvae only, $r=0.72, p=0.01$ for the data set with the artificial larvae included. Such a correlation analysis disregards the potential influence of various possible covariates (Table 3). However, those were proven not to have an effect on detection rank in respective logistic regressions (not shown).

Body size appeared to be the main determinant of colour pattern though the quantitative aspects of the pattern were sex-specific to a certain extent. As a most notable effect, the females largely lost their warning colouration (bright) after a certain threshold size: the contrasting yellow tufts were replaced by inconspicuously brownish colouration (dull) instead.

The higher repellence of the brightly coloured morph was confirmed in the experiments with bird predators. However, the difference was not particularly large and, importantly, the majority of the larvae were eventually attacked and consumed by the birds. This confirms the idea that even a classical black-yellow colouration, combined with hairiness, may not provide sufficient protection for aposematic larvae (Endler \& Mappes, 2004). Even though we only studied the responses of one bird species, the conclusion about the lack of complete protection can be viewed with reasonable confidence. First, great tits are significant predators of lepidopteran larvae throughout the Palearctic boreal zone, and second, results with different bird species appear to confirm the idea. In particular, the similarly looking larvae of other Orgyia species have been reported to be preyed on by numerous species of birds (Torgersen et al., 1984, 1990; Medina \& Barbosa, 2002). This leads to the conclusion that detectability might be a more important determinant of survival rate than acceptability, even for a larva whose appearance allows one to expect the opposite. In particular, aposematic larvae are not safe because bird species differ in their ability to discriminate between aposematic and non- aposematic prey (Exnerová et al., 2003), also the threshold signal strength that creates the aversion appears to vary (Exnerová et al., 2006). The birds' willingness to consume aposematic prey also strongly depends on their hunger level as the results of the current and some other studies show (Chai, 1986; Sandre \& Mappes, in prep.). It can also depend on their ability to overcome prey defences, both within (Bowers \& Farley, 1990) and between species (Exnerová et al., 2003), the presence of alternative prey (Hetz \& Slobodchikoff, 1988; Lindström et al., 2001, 2004), earlier experience (Endler, 1988; Lindström et al., 1999a, 2001; Exnerová et al., 2007), within-species genetic biases (Marples \& Brakefield, 1995), and more.

The incomplete protection its warning colouration provides to an Orgyia larva prompts one to focus on the effects of crypsis when studying the adaptive value of colour patterns. Quite unexpectedly, in a semi-natural setting, the bright larvae - most conspicuous at a short distance - were harder to find for human subjects than were the dull ones. It is hard to propose other explanation for such an outcome than the disruptive effect of the bright yellow hair tufts. The three-dimensional shape of the hair tufts enables them to "cut" the caterpillar's edges when viewed from different angles, impairing thus the edge detection by the viewer's eye (Stevens \& Cuthill, 2006). Furthermore, since disruptive colouration (Cott, 1940; Merilaita, 1998) is believed to be most effective with high contrast between pattern elements (Cott, 1940; Merilaita, 1998; Cuthill et al., 2005), the yellow tufted larvae can well have an advantage over the less conspicuous ones for this reason.

Notably, however, the detectability advantage of the bright morph over the dull morph was reversed at sizes over about $120 \mathrm{mg}$, which roughly corresponds to the natural switching point between these morphs. In particular, the largest larvae followed the intuitive pattern of the better detectability of the bright form over the dull. The likely explanation is that the effect of the conspicuousness of colour pattern exceeds the effect of the disruptive colouration. The size of the colourful tufts increases proportionally with body size, and the disruptive effect is therefore likely to be lost because of the increased size of the pattern elements. These results suggest that the interaction between colour pattern and larval body size in determining detectability might alone be sufficient to explain the switch between the bright and the dull morph at sizes of about $80 \mathrm{mg}$ (Fig. 1b).

Consistent with our results, it has been suggested that the submaximal conspicuousness exhibited by various noxious, distasteful or hairy caterpillars can be the result of combining the functions of warning display and camouflage (Endler, 1978; Ruxton et al., 2004; Tullberg et al., 2005). The conspicuousness of a colour pattern is a combined function of its coarseness and the viewing distance, so that coarser patterns will appear conspicuous at relatively long distances, where finer patterns are still cryptic. The aposematic effect, on the other hand, is greatest at the highest coarseness, i.e. the largest pattern 
elements. To combine these functions, an individual must display a colour pattern that is coarse enough to repel predators, but fine enough to prevent long-distance detection. Colour morphs that seem to exhibit this kind of dual function have been demonstrated in the case of swallowtail Papilio machaon (Tullberg et al., 2005), and suggested in several other species (Deml \& Dettner, 2003, Ruxton et al., 2004). We find it likely that this strategy is also used by the medium sized Orgyia larvae. As an aside, it is interesting to note the weak overall effect of size on the time to be found, which confirms the results of Mänd et al. (2007) suggesting a surprisingly minor overall effect of body size on the detectability of insects by visually searching predators.

An alternative explanation of the dominance of the dull colouration among the largest larvae could be based on the microhabitat change of the larvae preparing for pupation. In particular, many tree-feeding light green lepidopteran and sawfly larvae turn dark brownish before pupation, a fact that many entomologists are familiar with but only few appear to have reported (e.g. Wagner, 2006). Here a likely obvious adaptive explanation would be the improved camouflage of the brown larvae which descend the tree and wander on the soil in search of pupation site. The dull colouration of mature larvae of $O$. antiqua might thus be explained in the same way: $O$. antiqua larvae frequently (but perhaps not predominantly) pupate on tree trunks, and a bright larva spinning its cocoon may be most apparent to any predator against the background of a dark tree bark. However, the dependence of the bright vs dull colour switch on actual size rather than instar number (also when counted backwards) contradicts this idea. Even more importantly, most males pupate in the bright colour morph which is not what should be expected under the preparation for pupation hypothesis. Moreover, males are much less likely to develop dull colouration than females with an equal initial weight of an instar (Fig. 1b), though, for any given initial weight, males are more likely to pupate at the end of the instar than do females. However, this pattern is consistent with the camouflage hypothesis because females grow more than males during their last instar (Esperk \& Tammaru, 2006). The larvae might thus have been selected to "extrapolate" their final weights: during their last instar, females are more likely than males to exceed the critical limit when dull colouration becomes favourable, and may thus have been selected to change their colour well in advance.

At the present stage, we cannot propose an ultimate explanation for the switch from pied to bright colouration which occurs earlier in larval life. It is notable, however, that unlike the later switch from bright to dull, there is a wide range of body weights at which both pied and bright morphs occur at an approximately equal frequency. Such a pattern of seemingly random, stabile coexistence may be consistent with the scenario of frequency dependent selection maintaining stabile polyphenism, either on a genetic basis (Olendorf et al., 2006), or as a result of a coin-flipping plasticity (Cooper \& Kaplan, 1982; Meyers $\&$ Bull, 2002). An advantage of being different from the majority, indeed, is expected in this system, as larval densities are often high in O. antiqua (e.g. Paal, 1993; Hydén et al., 2006; personal observations of the authors), and bird predators are expected to develop a search image for the most frequent morph. This is especially important at high abundances of predators that do not learn to avoid brightly coloured Orgyia larvae (such as great tits), thus weakening the selection pressure towards monomorphism, which in other cases would enhance predator learning (Müller, 1879; Rowe et al., 2004).

In summary, even if the pattern of an ontogenetic change in larval colouration in $O$. antiqua is consistent with the hypothesis of a trade-off between acceptability and detectability, the situation may be explained solely by the size-dependent effect of detectability of different colour morphs. However, even if the role of acceptability to bird predators is not likely to be a major ultimate determinant of the colour pattern, it may still have a certain selective role. In particular, if the sole purpose of the distinctive colour pattern is in creating a disruptive effect, it would be hard to explain why the tufts of the bright morph are bright yellow, not just light yellow, and why there are bright red elements on the uncovered portions of the dark cuticula.

ACKNOWLEDGEMENTS. Our great thanks to volunteers who searched for caterpillars in the detectability experiment. We thank Tanel Esperk, Toomas Esperk and K. Jürgens for rearing the larvae. We are also grateful to the members of Nigula Nature Reserve administration, especially A. Leivits, and to I. and J. Tammekänd for assistance at Kabli Bird Station. This study was supported by Estonian Science Foundation grant $\mathrm{nr}$ 5746.

\section{REFERENCES}

Bernays E.A. \& Montllor C.B. 1989: Aposematism of Uresiphita reversalis larvae (Pyralidae). J. Lepid. Soc. 43: 261-273.

BLEST A.D. 1957: The function of eyespot patterns in Lepidoptera. Behaviour 11: 209-255.

Bonnet X., Aubret F., Lourdais O., Ladyman M., Bradshaw D. \& Maumelat S. 2005: Do "quiet" places make animals placid? Island vs. mainland tiger snakes. Ethology 111: 573-592.

Bowers M.D. \& Farley S. 1990: The behavior of gray jays, Perisoreus canadensis, towards palatable and unpalatable Lepidoptera. Anim. Behav. 39: 699-705.

Chai P. 1986: Field observations and feeding experiments on the responses of rufous-tailed jackamars (Glabula ruficauda) to free-living butterflies in a tropical rain-forest. Biol. J. Linn. Soc. 29: 161-189.

CHASE J.M. 1999: To grow or reproduce? The role of life-history plasticity in food web dynamics. Am. Nat. 154: 571-586.

COOPER W.S. \& KaPlan R.H. 1982: Adaptive "coin-flipping": a decision-theoretic examination of natural selection for random individual variation. J. Theor. Biol. 94: 135-151.

Cornell J.C., Stamp N.E. \& Bowers M.D. 1987: Developmental change in aggregation, defense and escape behavior of buckmoth caterpillars, Hemileuca lucina (Saturniidae). Behav. Ecol. Sociobiol. 20: 383-388.

Costa J.T., Gotzer D.A. \& Janzen D.H. 2003: Late-instar shift in foraging strategy and trail pheromone use by caterpillars of the neotropical moth Arsenura armida (Cramer) (Saturniidae: Arsenurinae). J. Lepid. Soc. 57: 220-229. 
Coтt H.B. 1940: Adaptive Colouration in Animals. Methuen, London, $508 \mathrm{pp}$.

Cuthill I.C., Stevens M., Sheppard J., Maddocks T., Párraga C.A. \& Troscianko T. 2005: Disruptive colouration and background pattern matching. Nature 434: 72-74.

Deml R. \& Dettner K. 2001: Comparative morphology and evolution of the funnel warts of larval Lymantriidae (Lepidoptera). Arthropod Struct. Dev. 30: 15-26.

Deml R. \& Dettner K. 2003: Comparative morphology and secretion chemistry of the scoli in caterpillars of Hyalophora cecropia. Naturwissenschaften 90: 460-463.

ENDLER J.A. 1978: Predator's view of animal color patterns. Evol. Biol. 11: 319-364.

ENDLER J.A. 1988: Frequency-dependent predation, crypsis and aposematic colouration. Phil. Trans. R. Soc. Lond. (B) 319: 505-523.

EndLer J.A. \& MAPPes J. 2004: Predator mixes and the conspicuousness of aposematic signals. Am. Nat. 163: 532-547.

EsPerk T. \& TAMmaru T. 2006: Determination of female-biased sexual size dimorphism in moths with variable instar number: the role of additional instars. Eur. J. Entomol. 103: 575-586.

Exnerová A., Landová E., Štys P., Fuchs R., Prokopová M. \& Cehláriková P. 2003: Reactions of passerine birds to aposematic and non-aposematic firebugs (Pyrrhocoris apterus; Heteroptera). Biol. J. Linn. Soc. 78: 517-525.

Exnerová A., Svádová K., Štys P., Barcalová S., Landová E. Prokopová M., Fuchs R. \& Socha R. 2006: Importance of colour in the reaction of passerine predators to aposematic prey: experiments with mutants of Pyrrhocoris apterus (Heteroptera). Biol. J. Linn. Soc. 88: 143-153.

Exnerová A., Štys P., Fučíková E., Veselá S., Svádová K., Prokopová M., Jarošík V., Fuchs R. \& Landová E. 2007: Avoidance of aposematic prey in European tits (Paridae): learned or innate? Behav. Ecol. 18: 148-156.

Forsman A. \& Merilaita S. 1999: Fearful symmetry: pattern size and asymmetry affects aposematic signal efficacy. Evol. Ecol. 13: 131-140.

Gamberale G. \& Tullberg B.S. 1996: Evidence for a peak-shift in predator generalization among aposematic prey. Proc. $R$. Soc. Lond. (B) 263: 1329-1334.

Gamberale G. \& Tullberg B.S. 1998: Aposematism and gregariousness: the combined effect of group size and colouration on signal repellence. Proc. R. Soc. Lond. (B) 265: 889-894.

Geffeney S., Brodie Jr. E.D., Ruben P.C. \& Brodie III E.D. 2002: Mechanisms of adaptation in a predator-prey arms race: TTX-resistant sodium channels. Science 297: 1336-1339.

Hagen S.B., Leinaas H.P. \& Lampe H.M. 2003: Responses of great tits Parus major to small tortoiseshells Aglais urticae in feeding trials; evidence of aposematism. Ecol. Entomol. 28: 503-509.

Hagman M. \& Forsman A. 2003: Correlated evolution of conspicuous colouration and body size in poison frogs (Dendrobatidae). Evolution 57: 2904-2910.

Hetz M. \& Slobodchikoff C.N. 1988: Predation pressure on an imperfect Batesian mimicry complex in the presence of alternative prey. Oecologia 76: 570-573.

Holopainen I.J., Tonn W.M. \& Paszkowski C.A. 1997: Tales of two fish: the dichotomous biology of crucian carp (Carassius carassius (L.)) in northern Europe. Ann. Zool. Fenn. 34: 1-22.

Hydén N., JiLG K. \& Östman T. 2006: Nationalnyckeln till Sveriges flora och fauna. Fjärilar: Ädelspinnare - toftspinnare, Lepidoptera: Lasiocampidae - Lymantriidae. ArtDatabanken, SLU, Uppsala, 480 pp.
KILTIE R.A. 1988: Countershading: universally deceptive or deceptively universal. TREE 3: 21-23.

Lindström L., Alatalo R.V., Lyytinen A. \& Mappes J. 2001: Predator experience on cryptic prey affects the survival of conspicuous aposematic prey. Proc. R. Soc. Lond. (B) 268: 357-361.

Lindström L., Alatalo R.V., Lyytinen A. \& Mappes J. 2004: The effect of alternative prey on the dynamics of imperfect Batesian and Müllerian mimicries. Evolution 58: 1294-1302.

Lindström L., Alatalo R.V. \& Mappes J. 1999a: Reactions of hand-reared and wild-caught predators toward warningly colored, gregarious, and conspicuous prey. Behav. Ecol. 10: 317-322.

Lindström L., Alatalo R.V., Mappes J., RiIPI M. \& Vertainen L. 1999b: Can aposematic signals evolve by gradual change? Nature 397: 249-251.

Littell R.C., Stroup W.W. \& Freund R.J. 2002: SAS for Linear Models. SAS Institute Inc, Cary, NC, 466 pp.

MADSEN T. 1987: Are juvenile grass snakes, Natrix natrix, aposematically coloured? Oikos 48: 265-267.

Marples N.M. \& BRAKefield P.M. 1995: Genetic variation for the rate of recruitment of novel insect prey into the diet of a bird. Biol. J. Linn. Soc. 55: 17-27.

Mänd T., TAMmaru T. \& Mappes J. 2007: Size dependent predation risk in cryptic and conspicuous insects. Evol. Ecol. 21: 485-498.

Medina R.F. \& Barbosa P. 2002: Predation of small and large Orgyia leucostigma (J.E. Smith) (Lepidoptera: Lymantriidae) larvae by vertebrate and invertebrate predators. Environ. Entomol. 31: 1097-1102.

Merilaita S. 1998: Crypsis through disruptive colouration in an isopod. Proc. R. Soc. Lond. (B) 265: 1059-1064.

MeYers L.A. \& Bull J.J. 2002: Fighting change with change: adaptive variation in an uncertain world. TREE 17: 551-557.

MostLer G. 1935: Beobachtungen zur Frage der Wespenmimikry. Z. Morphol. Ökol. Tiere 29: 381-454.

MÜlLER F. 1879: Ithuna and Thyridia: a remarkable case of mimicry in butterflies. Trans. Entomol. Soc. Lond. 1879: $\mathrm{xx}$-xxiv.

NilsSON M. \& ForSMAN A. 2003: Evolution of conspicuous colouration, body size and gregariousness: a comparative analysis of lepidopteran larvae. Evol. Ecol. 17: 51-66.

Olendorf R., Rodd F.H., Punzalan D., Houde A.E., Hurt C., Reznick D.N. \& Hughes K.A. 2006: Frequency-dependent survival in natural guppy populations. Nature 441: 633-636.

PAAL T. 1993: Pests and diseases of the cowberry (Vaccinium vitis-idaea L.). Aquilo (Ser. Bot.) 31: 35-39.

PAINE R.T. 1976: Size-limited predation: an observational and experimental approach with the Mytilus-Pisaster interaction. Ecology 57: 858-873.

PORTER J. 1997: The Colour Identification Guide to Caterpillars of the British Isles. Penguin, London, 288 pp.

Poulton E.B. 1888: Notes in 1887 upon Lepidopterous larvae. Trans. Entomol. Soc. Lond. 1888: 515-606.

Rowe C., Lindström L. \& LyYtinen A. 2004: The importance of pattern similarity between Müllerian mimics in predator avoidance learning. Proc. R. Soc. Lond. (B) 271: 407-413.

Ruxton G.D., Sherratt T.N. \& Speed M.P. 2004: Avoiding Attack: The Evolutionary Ecology of Crypsis, Warning Signals and Mimicry. Oxford University Press, Oxford, 249 pp.

Sandre S.-L., Tammaru T., Esperk T., Julkunen-Tittto R. \& MAPPES J. 2007: Carotenoid based colour polymorphism in a moth species: search for fitness correlates. Entomol. Exp. Appl. 124: 269-278. 
Sandre S.-L., Tammaru T., Vanatoa A. \& Esperk T. (in press): Maintenance of larval color polymorphism in Orgyia antiqua (Lepidoptera: Lymantriidae): evaluating the role of thermal adaptation. Envir. Entomol.

Sargent T.D., Millar C.D. \& Lambert D.M. 1998: The "classical" explanation of industrial melanism. Evol. Biol. 30 299-322.

Stevens M. \& Cuthill I.C. 2006: Disruptive colouration, crypsis and edge detection in early visual processing. Proc. $R$. Soc. Lond. (B) 273: 2141-2147.

Stimson J. \& Berman M. 1990: Predator induced colour polymorphism in Danaus plexippus L. (Lepidoptera: Nymphalidae) in Hawaii. Heredity 65: 401-406.

Tammaru T., Esperk T. \& Castellanos I. 2002: No evidence for costs of being large in females of Orgyia spp. (Lepidoptera, Lymantriidae): larger is always better. Oecologia 133: 430-438

Torgersen T.R., Ward T.J. \& VAN HoRn D. 1984: Avian predators of Douglas-fir tussock moth, Orgyia pseudotsugata (McDunnough), (Lepidoptera: Lymantriidae) in Southwestern Oregon. Environ. Entomol. 13: 1018-1022.
Torgersen T.R., Mason R.R. \& Campbell R.W. 1990: Predation by birds and ants on two forest insect pests in the Pacific Northwest. Stud. Avian Biol. 13: 14-19.

Tullberg B.S., Merilaita S. \& Wiklund C. 2005: Aposematism and crypsis combined as a result of distance dependence: functional versatility of the colour pattern in the swallowtail butterfly larva. Proc. R. Soc. Lond. (B) 272: 1315-1321.

Tutt J.W. 1896: British Moths. George Routledge, London, xii $+368 \mathrm{pp}$.

Ulmer B., Gillott C. \& Erlandson M. 2003: Conspecific eggs and bertha armyworm, Mamestra configurata (Lepidoptera: Noctuidae), oviposition site selection. Environ. Entomol. 32: 529-534.

Wagner D.L., Hossler E.W. \& Hossler F.E. 2006: Not a tiger but a dagger: the larva of Comachara cadburyi and reassignment of the genus to Acronictinae (Lepidoptera: Noctuidae). Ann. Entomol. Soc. Am. 99: 638-647.

Wiklund C. \& Sillén-Tullberg B. 1985: Why distasteful butterflies have aposematic larvae and adults, but cryptic pupae: evidence from predation experiments on the monarch and European swallowtail. Evolution 39: 1155-1158.

Received April 2, 2007; revised and accepted May 22, 2007 